\title{
Note
}

\section{Leprechaunism (Donohue syndrome): A case bearing novel compound heterozygous mutations in the insulin receptor gene}

\author{
Yuki Kawashima $^{1)}$, Rei Nishimura ${ }^{1)}$, Akari Utsunomiya ${ }^{2)}$, Reiko Kagawa ${ }^{2)}$, Hiroaki Funata ${ }^{1)}$, \\ Masanobu Fujimoto ${ }^{1)}$, Keiichi Hanaki ${ }^{1)}$ and Susumu Kanzaki ${ }^{1)}$ \\ 1) Division of Pediatrics \& Perinatology, Tottori University Faculty of Medicine, Yonago 683-8504, Japan \\ 2) Department of Pediatrics, Hiroshima University Graduate School of Biomedical Sciences, Hiroshima 734-8551, Japan
}

\begin{abstract}
Leprechaunism (Donohue syndrome) is the most severe type of insulin receptor (INSR) gene anomaly with the majority of patients surviving for only 2 years. We report a surviving 2 -year-old male with leprechaunism, bearing novel compound heterozygous mutations in the INSR. The patient is a Japanese boy with acanthosis nigricans, lack of subcutaneous fat, hirsutism, thick lips, gum hypertrophy and extremely high insulin levels $(6702 \mathrm{mU} / \mathrm{mL})$. He was as having identified novel compound heterozygous mutations in INSR (p.T910M and p. E1047K). At 24 day-old, recombinant human insulin-like growth factor 1 (rh-IGF1) treatment was started because of poor weight gain. At 2 years old, the patient's serum glucose level and $\mathrm{HbA1C}$ value had worsened, and both a bolus of rh-IGF-1 and a subcutaneous injection of a rapid-acting insulin analog after meals, in addition to $\alpha$-glycosidase inhibitor, were initiated from 2 years onward. Oxygen administration and biphasic positive airway pressure treatment were also initiated from 2 years old due to upper airway obstruction with adenoidal hypertrophy. In the experiments conducted using $\operatorname{COS} 7$ cells homozygously transfected with the INSR mutation, T910M INSR failed to process the proreceptor and decreased insulin-stimulated tyrosine phosphorylation. E1047K INSR resulted in a complete absence of insulin-stimulated tyrosine phosphorylation. These findings suggest the near absence of INSR in this patient. We consider that the rhIGF1 treatment contributed to his long survival, but it was not able to prevent his diabetic condition. Our report provides important insights into the function of INSR, and for the treatment of leprechaunism.
\end{abstract}

Keywords: Leprechaunism, Insulin receptor, Recombinant IGF1

LEPRECHAUNISM (DONOHUE SYNDROME) is an extremely rare, autosomal recessive disorder caused by a defective insulin receptor (INSR). It is characterized by insulin resistance and distinct clinical and facial features [1]. Leprechaunism is the most severe type of INSR disorder with the majority of patients surviving for only 2 years [1-4]. It was found that the exogenous supplementation of recombinant human insulin-like growth factor 1 (rh-IGF1) can rescue the defective INSR insulin pathway via IGF1 receptor (IGF1R) activation, resulting in prolonged patient survival [5]. In addition, functional analyses of the INSR gene revealed that the disease phenotype is directly

Submitted Aug. 7, 2012; Accepted Aug. 21, 2012 as EJ12-0289

Released online in J-STAGE as advance publication Sep. 9, 2012

Correspondence to: Yuki Kawashima, Division of Pediatrics \& Perinatology, Tottori University Faculty of Medicine, 36-1 Nishicho, Yonago 683-8504, Japan.

E-mail: yuki.kawashima@med.tottori-u.ac.jp correlated with the severity of the gene mutation $[2$, $3,6]$. Here, we report the case of surviving Japanese boy with leprechaunism who had novel, compound heterozygous mutations in the INSR gene (p.T910M and p.E1047K).

\section{Case Report}

The patient is a Japanese boy (first-born child) who was two years old at the time of this writing. His parents were healthy, and there was no family history of diabetes. At 8 days old, he was referred to our hospital because of poor sucking and low activity levels. He was delivered at 41 weeks of gestation with a birth weight of $1920 \mathrm{~g}$ (- $3.7 \mathrm{SD})$. His appearance was characteristic of leprechaunism, with acanthosis nigricans, lack of subcutaneous fat, decreased muscle, hirsutism, prominent eyes, low-set large ears, thick lips, and gum hypertrophy (Fig. $1 \mathrm{~A}$ ). Plasma glucose levels ranged 

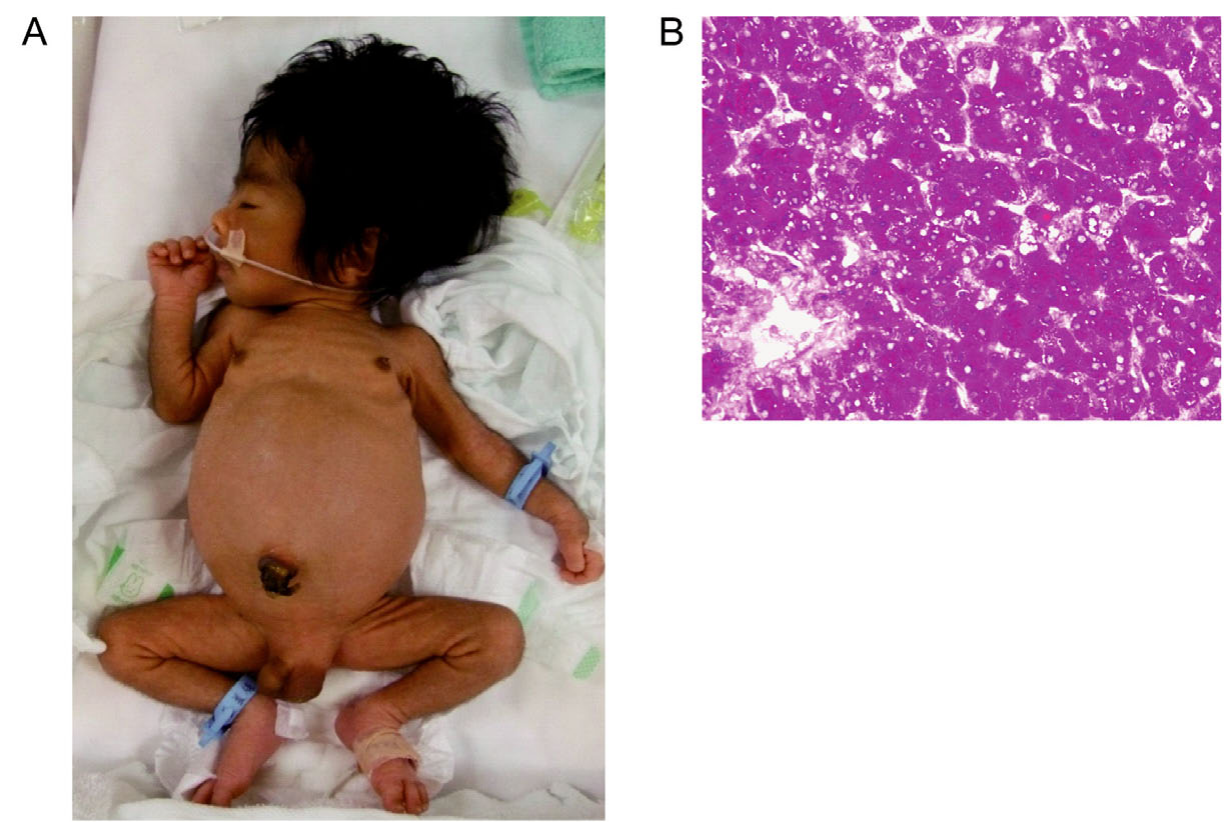

Fig. 1 A:Photograph of the patient with leprechaunism, at 8 days of age. The photo is approved by his parents in written form. B: Light micrographs of Periodic acid-Schiff (PAS) staining of liver tissues from the patient.

from $38 \mathrm{mg} / \mathrm{dL}$ in the fasting state to over $200 \mathrm{mg} / \mathrm{dL}$ at the postprandial state. The fasting plasma insulin level was significantly above average at $6702 \mathrm{mU} / \mathrm{mL}$. The results of all other laboratory tests were within normal range. From these findings, the patient was clinically diagnosed with leprechaunism, and we subsequently analyzed the patient's INSR gene.

At 24 days old, his weight gain was extremely poor and we began rhIGF1 treatment: rh-IGF1was subcutaneously injected, at a low concentration, twice a day and was gradually increased up to four times per day, and finally injected continuously at the dose of $1.0 \mathrm{mg}$ $/ \mathrm{kg} /$ day. Although the patient's serum insulin/glucose ratio and body weight improved, his weight was not normalized (Fig. 2). At 172 days old, we began a continuous rh-IGF1 subcutaneous infusion. At 1 month old, the patient exhibited pale stool, macrohematuria, extremely low levels of hepaplastin test (5\%), hyperbilirubinemia (direct bilirubin: $1.6 \mathrm{mg} / \mathrm{dL}$ ), and liver dysfunction (Aspartate transaminase: AST,100-235 IU/L and alanine aminotransferase: ALT, 15-80 IU/L). At 5 months old, scintigraphy tests revealed delayed biliary excretion, and a liver biopsy at 6 months old showed mild hepatitis, partial fibrosis, and accumulation of glycogen in the hepatocytes (Fig.1B). From these findings, the patient was diagnosed with cholestasis and coagulation disorder due to cholestasis. With the rhIGF1 injection treatment, the patient's vitamin $\mathrm{K}$ and ursodeoxycholic acid, his cholestasis and his liver dysfunction were improved (AST $97 \mathrm{IU} / \mathrm{L}$, ALT $35 \mathrm{IU} / \mathrm{L}$, T-bil $0.4 \mathrm{mg} / \mathrm{dL}$ ) at 1 year old.

At 2 years old, the patient's serum glucose level after meals and HbA1C value (Japan Diabetes Society) had worsened (> $600 \mathrm{mg} / \mathrm{dL}$ and $8.6 \%-9.4 \%$, respectively) despite the increased bolus of rh-IGF1 [0.03 mg/kg] after meals and the continuous subcutaneous infusion of rh-IGF1 [0.6 mg/kg/day]. Accordingly, the both bolus of rh-IGF-1 and a subcutaneous injection of a rapid-acting insulin analog (8 IU) after meals, in addition to the continuous subcutaneous infusion of rh-IGF1 [0.6 mg/ $\mathrm{kg} / \mathrm{day}]$ and $\alpha$-glycosidase inhibitor, were initiated from the patient's age of 2 years onward. His $\mathrm{HbA1C}$ value remains high $(9.7 \%$ at 2 years +1 month of age), and hypoglycemia in the fasting state continues. In addition, the patient suffered from pneumonia and asthmatic bronchitis several times and, developed an upper airway obstruction due to adenoidal hypertrophy. Oxygen administration and biphasic positive airway pressure treatment were initiated from 2 years onward. After the patient underwent a tonsillectomy at 2 years and 6 months old, his respiratory problems improved. 

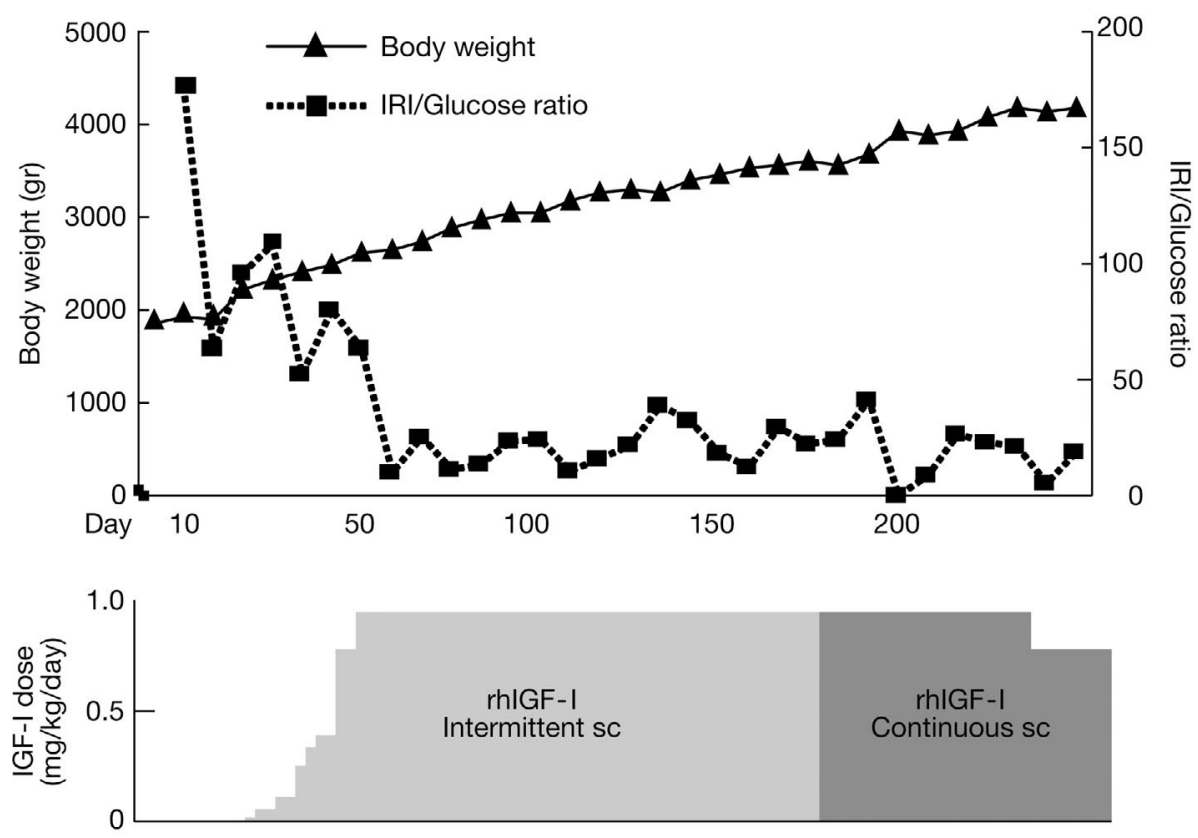

Fig. 2 The clinical course (body weight, insulin /glucose ratio) of the patient on rh-IGF1 treatment

\section{Materials and Methods}

\section{Sequence analysis of the INSR gene}

Genomic DNA was isolated from peripheral blood lymphocytes of the patient and his parents, and amplified by PCR as described [7, 8].

\section{Plasmid construction}

Flag tagged-pCMV-human INSR cDNA was provided by Dr. Masanori Iwaki (The University of Osaka, Osaka, Japan). A mutated INSR expression vector (p. T910M) was constructed by a $2919 \mathrm{C}$ to $\mathrm{T}$ (NM_000208.2, c. 2919 C $>$ T) point mutation using primers (5'T C T T G GAT G GAA3', where T is the mutation site), and a mutated INSR expression vector (p. E1047K) was constructed by a $3269 \mathrm{G}$ to $\mathrm{A}$ and $3271 \mathrm{G}$ to $\mathrm{A}$ (NM_000208.2, c.3269G $>$ A, C.3271G to A) point mutation using the primer (5'A A T A A G C C T C3', where $\mathrm{A}$ is the mutation site). All mutations were confirmed by DNA sequencing and performed by Life Technologies Japan (Tokyo, Japan).

\section{Immunoblotting analysis}

COS-7 cells $\left(0.5-1.0 \times 10^{6}\right)$ were transiently transfected with either the WT, T910M, or E1047KINSR construct with Lipofectamine 2000 (Invitrogen,Carlsbad, $\mathrm{CA}$ ), according to the manufacturer's protocol, and seeded into 60 -mm dishes with $10 \%$ Dulbecco's modified Eagle's medium (DMEM) (Wako Pure Chemical Industries, Ltd, Osaka, Japan) $6 \mathrm{~h}$ after transfection. Cells were washed twice with Hanks' balanced salt solution $12 \mathrm{~h}$ after seeding and starved for $2 \mathrm{~h}$ in a serum-free medium [DMEM]. The preparation of cell lysates, immunoprecipitation, and immunoblotting were performed as described [7]. We conducted each experiment at least three times, and the mean relative intensity of tyrosine phosphorylation from three different experiments was obtained (Fig. 4B).

\section{Statistical analysis}

Statistical analysis was performed using the Excel software and Student's $t$-test. The results are shown as mean \pm SE. $P<0.05$ was considered statistically significant.

\section{Results}

\section{Missense mutation (T910MorE1047K) of the INSR gene}

In the patient, we identified a heterozygous $\mathrm{C}$ to $\mathrm{T}$ substitution at position 2919 (NM_000208.2, c. 2919 $\mathrm{C}>\mathrm{T}$ ) that resulted in a threonine (ACG) to methionine (ATG) substitution at residue 910 (mature peptide numbering), and a heterozygous $\mathrm{G}$ to A mutation at position 3269 and 3271 (NM_000208.2, c.3269G $>$ A, C.3271G to A) that resulted in a glutamine (GAG) 

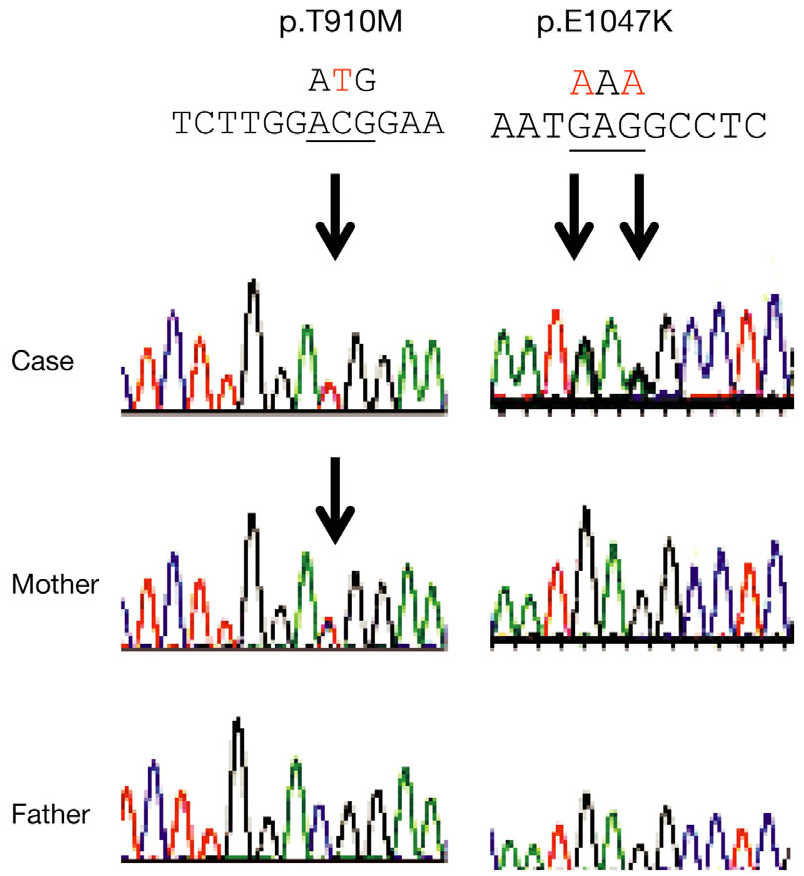

Fig. 3 The chromatogram of the INSR mutation in the proband and that of his parents

This chromatogram, obtained by direct sequencing of PCR products reveals compound heterozygous missense mutations in the proband. A C to $\mathrm{T}$ mutation at position 2919 (NM 000208.2, c. 2919 C $>$ T) resulted in the substitution of threonine (ACG) with methionine (ATG) in residue 910 (mature peptide numbering), and another heterozygous mutation $\mathrm{G}$ to $\mathrm{A}$ at position 3269 and 3271 (NM_000208.2, c.3269G $>$ A, C.3271G to $A)$, resulted in the substution of glutamine (GAG) with lysine (AAA) in residue 1047 (mature peptide numbering) of the INSR $\beta$ subunit.

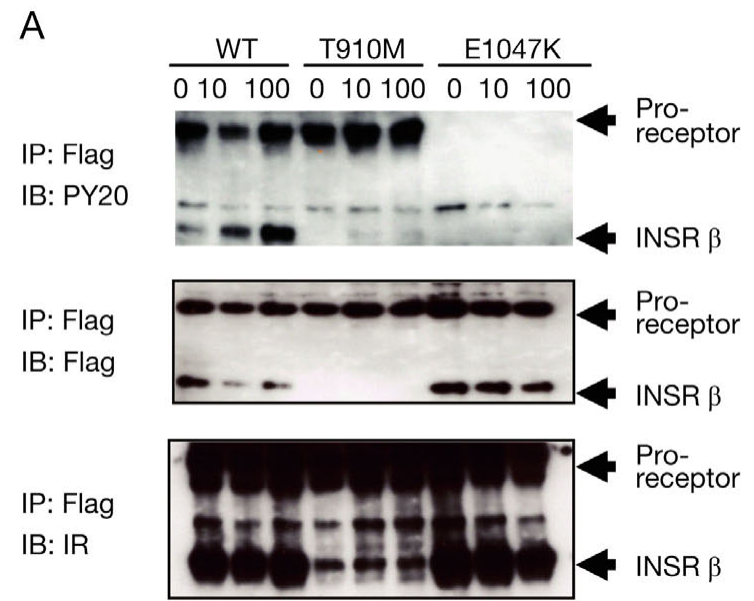

to lysine (AAA) substitution at residue 1047 (mature peptide numbering) in the INSR $\beta$ subunit (Fig.3). Although the INSR T910M mutation has been reported in patients with leprechaunism [9], this is the first report of an INSR E1047K mutation in a patient with leprechaunism. The E1047 mutation was not detected in our patient's parents, but a heterozygous T910M mutation was detected in his mother (Fig.3). Accordingly, the E1047 mutation is considered a de novo mutation. Since the patient's case presents the characteristic clinical findings of leprechaunism, his case is considered to be a compound heterozygous INSR gene mutation (p.T910M and p. E1047K).

\section{T910M and E1047K gene mutations diminish the} insulin-dependent phosphorylation of INSR

To understand the functions of these mutations, we studied the insulin-dependent autophosphorylation of the INSR $\beta$ subunit. In cells expressing E1047K, insulin-dependent autophosphorylation of E1047K INSR did not occur $(10 \mathrm{ng} / \mathrm{mL}, 0.00 \pm 0.01 v s .0 .86 \pm 0.16, p<$ $0.05 ; 100 \mathrm{ng} / \mathrm{mL}, ; 0.01 \pm 0.01$ vs. $0.97 \pm 0.01, p<0.05)$, and the autophosphorylation of T910M INSR was significantly decreased compared to WT $(10 \mathrm{ng} / \mathrm{mL}, 0.24 \pm$ 0.05 vs. $0.86 \pm 0.16, p<0.05 ; 100 \mathrm{ng} / \mathrm{mL}, 0.22 \pm 0.01$ vs. $0.97 \pm 0.05, p<0.05$ ) (Fig 4). Moreover, cells expressing T910M INSR had lower INSR levels compared to WT and E1047K-expressing cells, despite higher levels of the proreceptor, consistent with a previous report that T910M results in the failure to process the INSR prore-

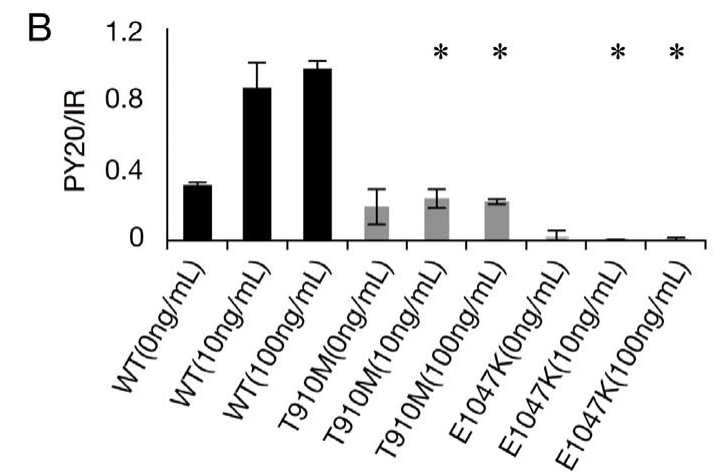

Fig. 4 Insulin-stimulated autophosphorylation of the INSR $\beta$ subunit in transiently transfected cells Cells were starved for $2 \mathrm{~h}$; stimulated with 0,10 , or $100 \mathrm{ng} / \mathrm{mL}$ Insulin for $5 \mathrm{~min}$; and lysed. Then, cell lysates were subjected to immunoprecipitation (IP) and immunoblotting (IB) analysis using the indicated antibodies. $A$ : Representative results of immunoblotting. $B$ : Relative intensity of tyrosine phosphorylation of INSR $\beta$, Results are shown as mean \pm SE. *, $p<0.05$. 
ceptor [9]. In light of these findings, it appears that these compound heterozygous mutations lead to dysfunctional insulin signaling that results in leprechaunism.

\section{Discussion}

We have described the case of a surviving patient with leprechaunism (Donohue syndrome) bearing novel compound heterozygous mutations in the INSR gene (p.T910M and p.E1047K), who is being treated with rh-IGF1.

We newly identified an INSR E1047K mutation in our patient, and we found that the mutation led to absence of insulin-dependent INSR autophosphorylation. Since the Glu 1047 insulin receptor has been reported to be an important residue for ATP binding and, as such, the phosphorylation of INSR [10, 11], our findings follow this line. However, the INSR T910M mutation has been reported in patients with leprechaunism [9], and has been reported that T910M INSR leads to a failure of processing the proreceptor, as is consistent with our data. Accordingly, these findings suggest that the patient's INSR function is nearly absent.

It is well known that the insulin and IGF receptors are structurally related and share common post-receptor signaling pathways. The rh-IGF1 treatment for leprechaunism exploits these commonalities, thus rescuing the failed INSR signaling found in leprechaunism $[5,12]$ and resulting in prolonged patient survival [5]. With the present patient, we also started rh-IGF1treatment early, with a resulting survival over 2 years. However, the rhIGF-1 treatment was not able to prevent the development of diabetes in the patient, therefore we started rapid insulin treatment and $\alpha$-glycosidase inhibitor. In addition, our patient is suffering from upper airway obstruction due to adenoidal hypertrophy, which might be related to a side effect of rh-IGF1 treatment. This sequence of events explains why IGF1 is not able to compensate for INSR.

Severe fasting hypoglycemia, as our patient also showed, is one of the characteristics of leprechaunism. This suggests an accelerated fasting state with rapid depletion of hepatic glycogen $[13,14]$. In contrast, other studies have found that patients with leprechaunism do not exhibit glycogen depletion, and they propose that, since insulin has a low affinity to IGF1R, the high insulin levels in humans may cause hypoglycemia by binding to IGF1R [15]. Consistent with this, the hepatic histological finding in our patient also revealed an accumulation of glycogen in hepatocytes. Notably, in our patient, hypoglycemia might have been induced by high insulin levels that result in IGF1R binding.

In conclusion, we report a surviving case of leprechaunism, bearing a novel heterozygous compound missense mutation (p.T910M and p. E1047K), who is being treated with rh-IGF1. The rhIGF1 treatment is thought to have contributed to the patient's survival, but it did not prevent diabetes. We suggest that to improve the condition of patient with complete INSR dysfunction, another treatment along with rhIGF1 may be effective.

\section{Disclosures}

All authors have no disclosures to report.

\section{References}

1. Kosztolanyi G (1997) Leprechaunism/Donohue syndrome/insulin receptor gene mutations: A syndrome delineation story from clinicopathological description to molecular understanding. Eur J Pediatr 156: 253255.

2. Whitehead JP, Soos MA, Jackson R, Tasic V, Kocova M, O'Rahilly S (1998) Multiple molecular mechanisms of insulin receptor dysfunction in a patient with donohue syndrome. Diabetes 47: 1362-1364.

3. Taylor SI (1992) Lilly lecture: Molecular mechanisms of insulin resistance. lessons from patients with mutations in the insulin-receptor gene. Diabetes 41: 14731490 .
4. de Bock M, Hayes I, Semple R (2012) "Donohue syndrome". J Clin Endocrinol Metab 97:1416-1417.

5. Nakae J, Kato M, Murashita M, Shinohara N, Tajima T, Fujieda K (1998) Long-term effect of recombinant human insulin-like growth factor I on metabolic and growth control in a patient with leprechaunism. J Clin Endocrinol Metab 83: 542-549.

6. Makino H, Taira M, Shimada F, Hashimoto N, Suzuki Y, Nozaki O, Hatanaka Y, Yoshida S (1992) Insulin receptor gene mutation: A molecular genetical and functional analysis. Cell Signal 4: 351-363.

7. Kawashima Y, Kanzaki S, Yang F, Kinoshita T, Hanaki K, Nagaishi J, Ohtsuka Y, Hisatome I, Ninomoya H, 
Nanba E, Fukushima T, Takahashi S (2005) Mutation at cleavage site of insulin-like growth factor receptor in a short-stature child born with intrauterine growth retardation. J Clin Endocrinol Metab 90: 4679-4687.

8. Seino S, Seino M, Bell GI (1990) Human insulin-receptor gene. partial sequence and amplification of exons by polymerase chain reaction. Diabetes 39: 123-128.

9. Kadowaki H, Takahashi Y, Ando A, Momomura K, Kaburagi Y, Quin JD, MacCuish AC, Koda N, Fukushima Y, Taylor SI, Akanuma Y, Yazaki Y, Kadowaki T (1997) Four mutant alleles of the insulin receptor gene associated with genetic syndromes of extreme insulin resistance. Biochem Biophys Res Commun 237: 516-520.

10. Haruta T, Takata Y, Iwanishi M, Maegawa H, Imamura T, Egawa K, Itazu T, Kobayashi M (1993) Ala1048-$>$ Asp mutation in the kinase domain of insulin receptor causes defective kinase activity and insulin resistance. Diabetes 42: 1837-1844.

11. Hubbard SR (2004) Juxtamembrane autoinhibition in receptor tyrosine kinases. Nat Rev Mol Cell Biol 5: 464471.

12. McDonald A, Williams RM, Regan FM, Semple RK, Dunger DB (2007) IGF-I treatment of insulin resistance. Eur J Endocrinol 157 Suppl 1: S51-6.

13. Roth SI, Schedewie HK, Bier DM, Conaway HH, Olefsky J, Rubenstein A, Elders MJ (1982) Hepatic ultrastructure in leprechaunism. hepatic ultrastructural evidence suggesting a syndrome with defective hepatic glucose release. Virchows Arch A Pathol Anat Histol 397: 121-130.

14. Bier DM, Schedewie H, Larner J, Olefsky J, Rubenstein A, Fiser RH, Craig JW, Elders MJ (1980) Glucose kinetics in leprechaunism: Accelerated fasting due to insulin resistance. J Clin Endocrinol Metab 51: 988-994.

15. Rother KI, Accili D (2000) Role of insulin receptors and IGF receptors in growth and development. Pediatr Nephrol 14: 558-561. 